\title{
Museu da PeSSOA: uMA EXPERIÊNCIA VIRTUAL DE VALORIZAÇÃO E RESGATE DAS HISTÓRIAS DE VIDA
}

\author{
Anna Clara Marotti Magalhães \& Leticia Maia Dias
}

\begin{abstract}
RESUMO
Este artigo apresenta uma discussão sobre os novos tipos de museus, principalmente voltados para a questão dos museus virtuais. Neste sentido, apresentamos como exemplo o Museu da Pessoa, que está totalmente inserido neste contexto, uma vez que desde a sua criação nasceu enquanto uma expressão viva de uma cultura visual digital em desenvolvimento, em que o acervo é composto por histórias de vida contadas voluntariamente por toda e qualquer pessoa. Posto isto, este museu ganha uma grande relevância no seio da sociedade brasileira, dado que através dele é possível trabalhar sob a perspectiva da Educação Patrimonial, valorizando o discurso oral e salvaguardando a memória e a identidade sociocultural de segmentos populacionais que durante muito tempo estiveram à margem, atribuindo sua real importância enquanto detentores do patrimônio.
\end{abstract}

\section{PALAVRAS-ChAVE}

Identidade; memória; Museu da Pessoa, virtualidade

\begin{abstract}
This article presents a discussion on the new types of museums, mainly focused on the question of virtual museums. In this sense, we present as an example the Museu da Pessoa [Museum of the Person], which is totally inserted in this context. Since its creation, it was created as a living expression of a developing digital visual culture, in which the collection is composed of life stories told voluntarily by all people. Given this, this museum gains a great relevance within the Brazilian society, since through it is possible to work from the perspective of Patrimonial Education, valuing the oral discourse and safeguarding the memory and the socio-cultural identity of population segments that for a long time were on the sidelines, attributing their real importance as owners of the assets.
\end{abstract}

KEYWORDS

Identity; memory; Museu da Pessoa; virtuality

\section{INTRODUÇÃo}

O Museu da Pessoa, localizado na cidade de São Paulo, foi criado em 1991 pela historiadora e atual diretora Karen Worcman, mediante a finalidade de relatar, divulgar e valorizar as memórias de todo e qualquer indivíduo, construindo assim, uma espécie de "Rede Internacional de Histórias de Vida". Desta forma, embora tenha emergido num período anterior à universalização e intensificação do uso das mídias ligadas à internet, o museu foi fundado com o intuito de ser essencialmente virtual: 
creio que estes três aspectos se tornaram bases para ideia do Museu da Pessoa, um museu virtual que tem por objetivo constituir um espaço de registro, preservação e disseminação de histórias de vida. (...) Neste sentido, considerar que narrativas de vida, toda e qualquer narrativa de vida pudesse ser considerada parte de um "museu" tornou-se parte estruturante da ideia na medida em que legitimava, valorizava e perenizava o que demais precioso possuímos, que é nossa memória (Worcman, 2011, p. 79).

Logo, para que não se percam ao longo do tempo, as narrativas precisam ser devidamente registradas e armazenadas. Sendo assim, inicialmente as histórias eram gravadas em vídeo e as informações referentes às mesmas eram colocadas em uma base de dados estruturadas em fichas. No entanto, atualmente o acervo encontra-se em uma plataforma digital, que pode ser facilmente acessada através do site' do museu.

Consequentemente, é importante salientar a relevância que o Museu da Pessoa vem adquirindo desde o ano de sua criação, no âmbito museológico e cultural brasileiro, já que possibilitou compreender os indivíduos como sujeitos efetivamente históricos e também detentores de memórias que são partes constituintes do patrimônio nacional. Ademais, essa nova forma museológica foi tão bem aceita no meio, que existem outros museus da Pessoa localizados no Canadá, Costa Rica, Estados Unidos e Portugal.

\section{MUSEU VIRTUAL: UMA NOVA FORMA DE USABILIDADE DOS MUSEUS}

De acordo com Pierre Lévy (1999), desde o final de 1980 e início de 1990, o mundo vem presenciando o surgimento de um movimento sócio-cultural que teve início com a ação de jovens universitários e profissionais americanos que com uma incrível velocidade se disseminou nos quatro cantos do universo. Deste modo:

sem que nenhuma instância dirigisse esse processo, as diferentes redes de computadores que se formaram desde o final dos anos 70 se juntaram umas às outras enquanto o número de pessoas e de computadores conectados à inter-rede começou a crescer de forma exponencial. Como no caso da invenção do computador pessoa, uma corrente cultural espontânea e imprevisível impôs um novo curso ao desenvolvimento tecno-econômico. As tecnologias digitais surgiram, então com a infra-estrutura do ciberespaço, novo espaço de comunicação, de sociabilidade, de organização e de transação, mas também novo mercado de informação e do conhecimento.

(Lévy, 1999, p. 32)

Antes de abordar a questão dos museus virtuais, cabe-nos aqui fazer uma breve discussão sobre o papel que os mesmos desempenham na sociedade contemporânea. É necessário, então, analisar as diversas modificações que sofreram - principalmente relativas à utilização e a evolução das novas mídias visuais digitais - para que

\footnotetext{
' Retirado de http://www.museudapessoa.net/pt/home
} 
posteriormente, possamos aferir acerca da maneira como estas instituições atuam no processo de formação e valorização sociocultural de uma determinada população.

De acordo com o Instituto Brasileiro de Museus ${ }^{2}$ (IBRAM), seguindo a Lei $n^{\circ} 11.904$ de 14 de janeiro de 2009, consideram-se museus:

as instituiç̧̃̃es sem fins lucrativos que conservam, investigam, comunicam, interpretam e expõem, para fins de preservação, estudo, pesquisa, educação, contemplação e turismo, conjuntos e coleções de valor histórico, artístico, científico, técnico ou de qualquer outra natureza cultural, abertas ao público, a serviço da sociedade e de seu desenvolvimento.

Como já salientado, são notórias as alterações que estes espaços sofreram no decorrer das últimas décadas, sobretudo no que se refere ao uso da tecnologia, o que determinou a necessidade de criar maiores condições de acessibilidade e comunicação com a comunidade como um todo:

a instituição museológica sofreu grandes alterações e foi alvo de salutar discussão que motivou novas formas de pensar o museu, havendo, agora, consciência de que necessita de se libertar do seu espaço tradicional e limitado, para se tornar acessível ao grande público. Cada vez mais o museu tem de se adaptar às necessidades da sociedade actual que se encontra em constante mutação. (Muchacho, 2005, p. 1540)

Por isso, os museus virtuais adotam diferentes mecanismos de estruturar e tornar acessível às informações sobre suas coleções, isto é, ao invés de as apresentarem em um espaço limitado fisicamente, disponibilizam as peças do seu acervo virtualmente:

o museu, como importante meio de comunicação, tem de aproveitar todo este desenvolvimento comunicacional e tecnológico, no sentido de satisfazer as novas correntes da museologia que se debruçam cada vez mais sobre o papel do museu na sociedade actual. Os novos media e em particular a internet são um instrumento precioso no processo de comunicação entre o museu e o seu público. A sua utilização como complemento do espaço físico do museu vem facilitar a transmissão da mensagem pretendida e captar a atenção do visitante, possibilitando uma nova visão do objecto museológico. (Muchacho, 2005, p. 1541)

Por conseguinte, os museus virtuais permitiram uma maior aproximação e comunicação com seu público. Este novo tipo de abordagem virtual, faz com que as visitas se tornem agradáveis e permitam novos tipos de experiências, possibilitando diferentes

\footnotetext{
${ }^{2}$ O Ibram foi criado em janeiro de 2009 pelo presidente Luiz Inácio Lula da Silva. A nova forma de governo está associada ao Ministério da Cultura que sucedeu o Iphan (Instituto Brasileiro Histórico e Artístico Nacional) nos direitos, deveres e obrigações relacionadas aos museus federais. O Ibram é responsável pela Política Nacional dos Museus (PNM) e pela melhoria dos serviços no setor, como o aumento de visitação e arrecadação dos museus, fomento de políticas e de preservação de acervos e criação de ações integradas entre os museus brasileiros, além de ser responsável pela administração de 29 museus. Retirado de http://www.museus.gov.br/
} 
formas de pensar e adquirir conhecimento (Simões, Bezerra \& Henriques, 2004). Vale salientar que, além dos museus virtuais que já utilizam a internet como forma de divulgação e marketing, muitos museus tradicionais estão adotando essa nova tecnologia no sentido de promover uma maior interação com seu público, além de utilizarem o espaço virtual como ferramenta de divulgação:

além da criação de sites com informações sobre o seu acervo, as instituições museológicas utilizam a internet também para divulgar boletins informativos, emails, catálogos, troca de informações entre especialistas, etc., de forma a divulgar o trabalho desenvolvido. A internet vem possibilitar uma maior interacção com o público e com os especialistas, possibilitando uma rede de troca de experiências e conhecimentos entre instituições com objectivos semelhantes ou convergentes. Na verdade, quase que podemos afirmar que se realiza uma nova visita, abrangendo determinados objectos e percursos expositivos que não foi possível realizar no espaço museológico tradicional. Quando se passa para o campo virtual, o campo de acção alarga-se dando origem a múltiplos percursos interactivos. Outra forma de utilização da internet são as parcerias institucionais, em que um determinado museu convida outras instituições a participar com conteúdos específicos, criando exposições virtuais, com conteúdos culturais e patrimoniais de vários museus. (Muchacho, 2005, p. 1542)

\section{Museu da Pessoa enquanto eXPeriência de museu Virtual}

As duas últimas décadas evidenciaram um rápido e intenso avanço tecnológico que transformou o campo da atuação e da pesquisa museológica, dado que as mídias visuais digitais vinculadas à Internet passaram a ser usadas não apenas como objetos meramente auxiliares, mas principalmente como fontes.

Todavia, como salienta o sociólogo e filósofo Pierre Lévy (1999, p. 126), se a internet constitui o grande oceano do novo planeta informacional, é preciso lembrar dos muitos rios que a alimentam: redes independentes de empresas, de associações, de universidades, sem esquecer as mídias clássicas (bibliotecas, museus, jornais, televisão etc.).

Assim, as instituições museológicas precisam desenvolver mecanismos que possibilitem a incorporação e adaptação destas novas mídias digitais, de maneira a potencializar a aquisição dos dados e a linguagem com que dialogam com o público, tornando estes dados mais acessíveis.

Em 1984, foi realizado na cidade de Quebec no Canadá o $1^{\circ}$ Atelier Internacional de EcoMuseus/ Nova Museologia , mediante o objetivo de "aprofundar e rever conceitos e encorajando ao mesmo tempo novas práticas museológicas" (Moutinho, 1989 , p. 56). Na proposta inicial estava assim estabelecido:

a museologia deve procurar, num mundo contemporâneo que tenta integrar todos os meios de desenvolvimento, estender suas atribuições e funções 
tradicionais de identificação, de conservação e de educação, a práticas mais vastas que estes objetivos, para melhor inserir sua ação naquelas ligadas ao meio humano e físico. Para atingir este objetivo e integrar as populações na sua ação, a museologia utiliza-se cada vez mais da interdisciplinariedade, de métodos contemporâneos de comunicação comuns ao conjunto da ação cultural e igualmente dos meios de gestão moderna que integram os seus usuários. (Declaração de Quebec, 1984).

Esta vertente denominada de "Nova Museologia" voltada para o desenvolvimento comunitário, a interdisciplinaridade e, principalmente, a compreensão dos indivíduos como sujeitos sociais, passa a ser constantemente adotada, em contraposição à "Museologia Clássica" baseada na valorização dos artefatos museológicos e de suas coleções, sem dar a real importância à ação dos indivíduos ao longo do processo de criação e aquisição dos mesmos:

na verdade a expressão "nova museologia" é uma espécie de "discurso guarda-chuva", abrigando posições diferentes mas que mantêm em comum sua oposição ao que seria o museu "tradicional". Menos que um discurso com fronteiras disciplinares bem definidas, trata-se antes de tudo de um "movimento" que veio a afetar amplamente os padrões de formação de profissionais de museus e colocar em questão o papel social dessas instituições em diversos países, incluindo-se o Brasil. Segundo os teóricos da "nova museologia", os museus devem assumir a sua função eminentemente social e superar os limites de uma concepção de cultura restrita à produção e circulação de bens culturais da elite, projetando-se assim como instituições afinadas com uma sociedade democrática. O "museu tradicional" seria elitista e voltado para si mesmo, distanciado do cotidiano dos indivíduos e dos grupos que compõem as modernas sociedades. (Gonçalves, 2007, p. 89)

É nesta conjuntura de emergência da chamada Nova Museologia e do avanço das mídias visuais digitais que o Museu da Pessoa foi fundado. Ao longo do artigo, vamos discorrer acerca das questões relacionadas à memória, identidade sociocultural e à Educação Patrimonial como aspectos que consideramos primordiais para a compreensão do Museu da Pessoa.

\section{Museu da Pessoa: Memória e identidade sociocultural}

No decorrer das décadas de 1970 e 1980, a questão da memória e do patrimônio começou a ganhar notoriedade no campo das ciências humanas, visto que no contexto internacional, marcado pela Guerra Fria, pelos processos de independência na África e Ásia e pelas Ditaduras Militares, instauradas especialmente nos países latino-americanos, os discursos de memórias passaram a ser utilizados por movimentos sociais e 
culturais no sentido de resgatar a importância da historicidade e das tradições existentes no passado:

um dos fenômenos culturais e políticos mais surpreendentes dos anos recentes é a emergência da memória como uma das preocupações culturais e políticas centrais das sociedades ocidentais. Esse fenômeno caracteriza uma volta ao passado que contrasta totalmente com o privilégio dado ao futuro, que tanto caracterizou as primeiras décadas da modernidade do século XX. (Huyssen, 2000, p. 9)

Neste contexto, a transição da década de 90 para o início do século XXI evidenciou o avanço e o aperfeiçoamento das mídias digitais que ocasionou, além da aceleração das informações, uma transformação profunda na percepção do tempo e do espaço, em que o presente "no mesmo momento em que se faz, deseja olhar-se como já histórico, como passado" (Hartog, 2014, pp. 149-150). Este imediatismo, que determina aos fatos recentes uma pequena duração e permanência em nosso cotidiano, acabou por influenciar no processo de formação e conservação das nossas próprias memórias, que tendem a se perder e descartar rapidamente.

Desta maneira, esse resgate da memória e de seus discursos, passou a fazer parte também do âmbito museológico, já que, segundo o filósofo alemão, Hermann Lübbe (citado em Huyssen, 2000, p. 26), a partir de 1980, tornou-se perceptível um processo de musealização, restrita não apenas ao ambiente do museu, mas em todas as partes da vida cotidiana. Logo, "precisa-se da memória e da musealização, juntas, para construir uma proteção contra a obsolescência e o desaparecimento, para combater a nossa profunda ansiedade com a velocidade de mudança e o contínuo encolhimento dos horizontes do tempo e do espaço" (Huyssen, 2000, p. 28).

Portanto, desde 1980 é possível observar que os centros de memória, arquivos e museus estão sujeitos a um processo contínuo de criação e ressignificação, sendo a conservação e a valorização do patrimônio (seja ele material ou imaterial), e suas relações com a memória, questões cada vez mais discutidas no tempo presente, não apenas na esfera acadêmica, mas colocadas também a serviço da sociedade.

Contudo, a memória ganha importância na medida em que mediante o imediatismo referenciado pelo historiador François Hartog (2014), a sociedade contemporânea reforça a necessidade de valorização e preservação das suas memórias como forma de acesso ao passado, ressaltando a atuação dos museus enquanto lugares de construção, divulgação, resgate e experiência de memórias.

Além disso, ao tratar da memória no âmbito no Museu da Pessoa faz-se necessário salientar a importância que a oralidade e a visualidade possuem como principal forma de transmissão das informações, uma vez que o acervo é composto pelas histórias de vida contadas pelas próprias pessoas, sendo gravadas em vídeo e disponibilizadas virtualmente.

De acordo com o historiador Joseph Ki-Zerbo (1979, p. 8), "é a tradição oral que (...) que veste, colore e irriga de sangue o esqueleto do passado". É neste aspecto que a memória configura-se então enquanto recurso fundamental usado pelas sociedades 
de tradição oral, como por exemplo as africanas, cuja cadeia de transmissão do conhecimento de geração em geração é uma fundamental para que a memória ajude na reconstrução do acontecimento ou da narrativa em sua totalidade: é uma espécie de filme que se desenrola do princípio ao fim, mas faz-se no presente. Não se trata apenas de recordar, mas de trazer ao presente um evento passado do qual todos participam, tanto o narrador como sua audiência (Hampaté Bâ, 2010, p. 208).

É assim que a ação do Museu da Pessoa adquire suma importância, pois a partir das trajetórias de vida das pessoas é possível recuperar e preservar o conhecimento acerca da memória e da identidade sociocultural. Destarte, através da oralidade, estas histórias mantém-se vivas, transformando-se em registros dinâmicos que podem ser constantemente rememorados virtualmente, confirmando as palavras do escritor e especialista em oralidade Amadou Hampaté Bâ (2010), que considera a tradição oral como uma tradição viva.

Neste sentido, podemos enfatizar também a relevância que o Museu da Pessoa vem adquirindo no âmbito da pesquisa acadêmica, visto que configura-se enquanto um rico objeto de estudo. Como exemplo, podemos citar o trabalho da historiadora e mestra em Museologia Social, Rosali Maria Nunes Henriques, que em sua dissertação (2004) analisa o referido Museu, mediante a perspectiva da Memória, da Museologia e da Virtualidade. Henriques desenvolve então um estudo teórico que se evidencia como o pioneiro no que se refere ao tratamento mais aprofundado acerca deste Museu, uma vez que "é uma experiência de museu virtual que merece uma reflexão sobre suas atividades e sua trajetória" (Henriques, 2004, p. 9).

Logo, o Museu da Pessoa permite que o público e as próprias pessoas que narraram suas histórias possam exercer continuamente o ato de rememorar que, de acordo com Huyssen (2000, p. 67) dá forma aos nossos elos com o passado, e nos define no presente, já que, enquanto indivíduos e parte integrantes de sociedades, necessitamos do passado para construir e ancorar nossas identidades, alimentando nossa visão de futuro:

a memória é a vida, sempre carregada por grupos vivos e, nesse sentido, ela está em permanente evolução, aberta à dialética da lembrança e do esquecimento (...) é um fenômeno sempre atual, um elo vivido no eterno presente(...) porque é afetiva e mágica, a memória não se acomoda a detalhes que a confortam; ela se alimenta de lembranças vagas, telescópicas, globais ou flutuantes, particulares ou simbólicas, sensível a todas as transferências, cenas, censura ou projeções (...) A memória instala a lembrança no sagrado, (...) emerge de um grupo que ela une. (Nora, 1993, p. 9)

As nossas memórias possuem uma natureza diversa, podendo ser coletivas ou individuais. Porém, elas se entrelaçam na medida em que manifestam características identitárias e momentos que são partilhados socialmente, o que transforma a memória em um fenômeno essencialmente social e também cultural.

Consequentemente, os museus, segundo o historiador Andreas Huyssen, "se mantém como um espaço e um campo para reflexões sobre a temporalidade, a subjetividade, 
a identidade, e a alteridade" (1996, p. 226). Desta forma, a questão da identidade surge de forma quase que intrínseca a memória, visto que:

a memória é essencial a um grupo porque está atrelada à construção de sua identidade. Ela é o resultado de um trabalho de organização e de seleção do que é importante para o sentimento de unidade, de continuidade e de experiência, isto é, de identidade. (Alberti, 2005, p. 167)

Esta identidade pode então ser expressa a partir de um sentimento em comum, de uma noção de identificação compartilhada por indivíduos pertencentes a um grupo social, cultural ou nacional. Entretanto, de acordo com o antropólogo Roberto DaMatta, a verdadeira identidade não é aquela criada em torno de manifestações nobres e oficiais de auto-reconhecimento, e sim a visão do povo, da condição humana, dos gostos e costumes, pois as identidades são flutuantes e não substâncias. Assim sendo, a identidade:

é país, cultura, local geográfico, fronteira e território reconhecidos internacionalmente, e também casa, pedaço de chão calçado com o calor de nossos corpos, lar, memória e consciência de um lugar com o qual se tem uma ligação especial, única, totalmente sagrada. É igualmente um tempo singular cujos eventos são exclusivamente seus, e também temporalidade que pode ser acelerada na festa de carnaval; que pode ser detida na morte e na memória e que pode ser traduzida de volta na boa recordação. (DaMatta, 2001, pp. 11-12)

A questão da memória está intrinsecamente atrelada à questão da identidade. De acordo com a especialista em bens culturais, Luciana Figueiredo Avelar (2015), os objetos, coleções e os museus são utilizados para representação simbólica na afirmação de identidades pessoais e coletivas permitindo, assim, a construção social da memória.

A memória configura-se, então, como parte importante do sentimento de identidade expresso pelas pessoas por meio das histórias contadas e arquivadas no Museu da Pessoa, pois somente através da memória é possível conservar "certas informações, referentes a um conjunto de funções psíquicas que permitem ao indivíduo atualizar impressões ou informações passadas, ou reinterpretadas como passadas" (Le Goff, 2003, p. 419). Os processos de aquisição, organização e seleção e esquecimento dos momentos constituintes da nossa memória não são fixos; ocorrem antes de maneira distinta e complexa em cada indivíduo, sendo possível uma constante ressignificação por parte dos mesmos. Por isso, "o lugar de memória é um lugar duplo: de excesso, fechado sobre si mesmo, fechado sobre sua identidade, recolhido sobre seu nome, mas constantemente aberto sobre a extensão de suas significações" (Nora, 1993, p. 21).

Considerando a relação existente entre memória e identidade sociocultural, pode-se dizer que o Museu da Pessoa consolida-se enquanto uma entidade profundamente comprometida com o processo de valorização das narrativas de vida enquanto manifestações e construções sociais, identitárias e memoriais. Deste modo, essa preocupação expressa pelo Museu em socializar a história de toda e qualquer pessoa, ganha uma 
grande potencialidade se trabalhada mediante a perspectiva da educação patrimonial, já que:

por meio de atividades educativas podemos transformar as pessoas, o que seria dar um passo além de formar somente coleções, que não deveria ser a finalidade última desses espaços culturais. $O$ trabalho com a comunidade tem que ganhar uma relevância maior. Um museu que trabalha no campo dos direitos humanos proporciona uma experiência com a emoção, e é necessário um vínculo emocional para aprender. (Miziara, 2016, p. 234)

\section{A participação comunitária na formação do Museu da Pessoa}

Durante a abertura do Museu do Louvre para as grandes massas durante o século XIII na Europa, deu-se início a um período de criação de novos tipos de museus, diferentes dos modelos tradicionais. O cientista suíço Charles Bonstetten, em 1790, foi o pioneiro, ao mostrar que o museu poderia ser vivenciado pelas pessoas através de uma exposição feita ao ar livre, composto por diversas casas que remetiam a determinados períodos da história, equipadas de móveis e apetrechos que lembravam seu tempo.

No entanto, só em meados do século XIX, os museus a céu aberto passaram a ser criados na Escandinávia. Estes tipos diferenciados de museus adquirem grande importância, a partir do momento que suas visitas inter-relacionam a experiência educacional com a recreação.

Em 1969, já no bojo da emergência da Nova Museologia, surge na Dinamarca o Museu de Lejte, fundado sobre um sítio arqueológico. Esse museu se tornou um atelier, pois as pessoas que lá iam, não só observavam os objetos expostos, mas também assistiam à sua utilização e, por sua vez, usavam eles mesmos estes artefatos. Mediante o revisionismo que invade a esfera da museologia, os museus deixam de ser direcionados somente aos objetos existentes em seu ambiente físico e passam a se voltar para o contexto de produção dos mesmos, atribuindo maior significado à sociedade e às experiências individuais como fontes essenciais de memória.

De forma semelhante à experiência do Museu de Lejte, que transformou o modo de vivenciar o espaço, o Museu da Pessoa também evidenciou um tipo de abordagem que tornou a comunicação e o acesso ao público mais dinâmico. O Museu da Pessoa consolidou-se, então, como um "museu virtual e colaborativo" que valoriza a diversidade cultural e a história de cada pessoa como patrimônio da humanidade contribuindo para a construção de uma cultura de paz (Miziara, 2016, p. 237).

Os pequenos museus, voltados para comunidades menores e dedicados à preservação do patrimônio de um território limitado, ganharam força em meados do século $X X$, durante o período de pós-guerra. Em contrapartida, nos Estados Unidos, mais precisamente nos guetos negros de Washington e Nova lorque, emergiram os denominados "museus vizinhanças" que tinham como principal objetivo apresentar para a comunidade uma explicação de quem elas são, de onde elas vieram, o que elas conquistaram, quais os seus valores e suas necessidades. 
Tendo em vista estes acontecimentos, os museus passaram por intensas modificações ao longo do tempo, e somente a partir do século XX, deixaram de direcionar seus esforços na constituição de coleções, que por si só não possuíam real importância para os contextos social e comunitário. Por conseguinte, ao desenvolverem uma perspectiva de valorização social, tornou-se possível incluir as pessoas no processo de construção museológico, visto que são elas que dão sentido aos objetos presentes nestas instituições:

a participação é incentivada e indispensável na concepção do museu. Este, embora existente fisicamente na forma de um museu tradicional, com exposições sempre renovadas, tem a sua área de atuação ampliada, interagindo com e valorizando todos os tipos de atividades locais, festas típicas, eventos religiosos, encontros da terceira idade para a leitura de poesia, de maneira a integrar verdadeiramente a vida dos residentes. O museu se torna um catalisador da evolução social, com suas ações focadas no cotidiano. Todas as exposições são produzidas pela equipe do museu, mas idealizadas em conjunto com a comunidade. (Soares \& Scheiner, 2009, p. 9)

Neste sentido, a participação de pessoas comuns na formação do Museu da Pessoa é essencial, visto que ele é construído a partir das trajetórias de vida e das memórias de grupos que durante muito tempo estiveram totalmente excluídos não apenas da sociedade, mas principalmente do processo de escrita da história nacional, a história considerada como oficial e que ainda hoje predomina no contexto escolar. Logo, o museu busca aproximar e demonstrar a estas pessoas que suas histórias são importantes na construção de uma identidade social e cultural brasileira e que, por isso, são também detentores de patrimônio e agentes históricos:

esse é o objetivo do Museu da Pessoa: um mundo onde a tecnologia seja utilizada para articular as narrativas e incentivar cada pessoa, grupo ou comunidade a ser autor de sua história - própria e coletiva. Podemos vislumbrar um futuro em que a narrativa histórica da sociedade possa conter múltiplas "vozes", incluindo, sem hierarquia, histórias de vida de indivíduos de todos os segmentos da sociedade e onde a história de cada um será um ponto de nossa teia social. (Citado em Miziara, 2016, pp. 238-239)

A participação desses indivíduos é feita de forma comunitária, na qual o museu lhes demonstra a sua real importância e de que são detentores de uma memória ali valorizada. Podemos verificar isso a partir do discurso da líder quilombola Maria dos Prazeres Campos dos Santos, moradora da região metropolitana de Fortaleza, que contou sua história ao Museu da Pessoa em novembro de 2014:

a minha casa da infância tinha móveis. As camas eram feitas de vara. Colocava uns paus enfiados, uma vara encima e as folhas de junco, uma planta que dá à beira d'água - que ficava quentinha e confortável. Assim era o 
colchão. Quando era na época do inverno, que ficava tudo molhado, o piso era a folha - não tinha piso, era só o barro batido. Colocávamos aquelas folhas para podermos ficar com um pouco mais de conforto. (...) Sempre moramos perto, uns dos outros. Sempre foi assim, porque tem muita terra. Mas o ponto é esse: uns casam, mas as casas vão ficando sempre aqui, juntas. (...). Nem todo mundo tinha o café, tampouco a farinha. Poucos tinham. Mas nós aqui sempre tivemos espírito de coletividade quando estava faltando na casa do outro. Por exemplo, se eu tinha dois quilos de arroz e o outro tinha dois quilos de farinha, trocávamos: "Tu fica com a farinha que eu fico com o arroz". E assim vivia todo mundo nessa coletividade 3 .

A seguir ela conta sobre as ações dos fazendeiros que objetivavam retirar a comunidade quilombola de suas terras:

desde criança, participei da luta pela permanência da comunidade quilombola Sítio do Cercadão frente ao interesse de fazendeiros. Isso porque na década de 1970 os fazendeiros resolveram mexer conosco, pois aqui ninguém tinha documento da terra. Eles mexeram, queriam tomar e nos tirar daqui. Eles cercavam durante o dia, mas durante a noite arrancávamos tudo e queimávamos. Nessa época tinha o Moraes, uma pessoa rica, que morava em Icaraí, que deu um apoio pra nós. Ele comprava gasolina. Ele viu todo o nosso procedimento, aquela luta e tentou nos ajudar - entre aspas, porque em troca disso ele ficou com um monte de terra, dando o papel de usucapião. Era para termos uma área reservada para nós, esse pedaço que temos hoje, mas ele tomou. Icaraí era daqui e ele tomou quase tudo. Mas, graças a Deus, estamos em paz, com o pouco que temos ${ }^{4}$.

No decorrer das transformações que os museus passaram, é notório que eles são construídos através das experiências que um povo vive e/ou viveu em um dado lugar. $O$ Museu da Pessoa está inserido neste novo modelo de museu, mas se distingue dos demais na medida em que as pessoas, de forma voluntária, participam como protagonistas, o que permite que suas memórias sejam preservadas e divulgadas, sendo compreendidas como fontes do patrimônio e do saber histórico nacional.

Enfim, o Museu da Pessoa demonstra à sociedade contemporânea que existem uma grande multiplicidade de histórias, que não se restringem apenas àquelas presentes nos livros e/ou apresentadas em diferentes formas físicas através de peças em museus, já que as memórias individuais podem ser elementos integrantes e - no caso específico do Museu da Pessoa - essenciais para a construção da própria instituição e do conhecimento que ela transmite.

\footnotetext{
${ }_{3}^{3}$ Retirado de http://www.museudapessoa.net/pt/conteudo/historia/quando-vou-rezar-peco-licenca-a-natureza-96217

4 Retirado de http://www.museudapessoa.net/pt/conteudo/historia/quando-vou-rezar-peco-licenca-a-natureza-96217
} 


\section{Histórias de vida: A eXPeriênCia memorial e EdUCACional do Museu da Pessoa}

Huyssen (2000) acredita que a crescente aceleração das inovações tecnológicas, sobretudo vinculadas às mídias de informação digitais, tem como principal aspecto temporal a amnésia, que caracteriza a nossa cultura contemporânea e justifica o grande fascínio pela memória e pelo passado. Sendo assim, os museus, monumentos, memoriais, vídeos e produções em gerais que abordam temáticas vinculadas à memória como, por exemplo, a do Holocausto, são frequentes no que ele denomina como cultura memorial pós-moderna. Por isso, as histórias de vida que fazem parte do acervo do Museu da Pessoa permitem dar um protagonismo efetivo aos indivíduos comuns que durante muito tempo permaneceram distantes dos processos de formação e construção da esfera museológica.

Destarte, a abordagem adotada pelo referido museu fez com que o público deixasse de ser um mero observador, tornando-se um sujeito participativo do próprio museu. Podemos observar isso no discurso de Dona Raimunda Nascimento (2014) que é descendente dos povos Tremembé, mas também se sente Tapeba e é reconhecida como uma liderança desse povo. Ela conta sobre a vida sofrida que teve na infância, as transformações do local em que ela vive e a função de curandeira que lhe foi atribuída por ela ser detentora de saberes populares relativos à utilização de ervas medicinais:

de primeiro tinha umas ameixeiras, onde ficava um barranco lá em cima, juntava água debaixo. Hoje em dia esse barranco não existe mais. Porque não existe mais a mata, não existe mais as ameixeiras, o pessoal cavou, ficou só a lagoinha das orelhas de burro, mas bem pequenininha. O resto encheu tudo de orelha de burro, é um pauzinho que nasce, que tem as oreinhas assim, pra cima, direitinho umas oreias. Aí a gente apelidou ela por Lagoinha das Orelhas de Burro. Mas de primeiro tinha tanto pássaro aqui! Muito passarinho, uma mata grossa. E a gente ia pra lá. Era como se a gente ali de baixo não desse, não corresse perigo pra eles, como na verdade não corria, não, que ninguém tinha coragem de sair matando passarinho $E$ a gente brincava lá na sombra, era uma sombra, cantarola de pássaro que estralava. E, às vezes, eu fico lembrando daquilo ali. Muitas coisas (suspiro, emocionada), que se foi na criancice da gente. Do que a gente sente falta, essa é uma. Da falta da participação da gente com a natureza, que hoje, como você vê, mata, ninguém tem mata. Animal você só vê cantar só assim, preso na gaiola. Antigamente passava uma multidão de periquito aí, hoje a gente vê um periquitinho assim, preso nas gaiolas. Essas poucas coisas boas que a gente tinha e não tem mais. Hoje em dia a gente ficou de um jeito que a gente não tinha mais onde plantar, e quando uma pessoa plantava perdia a metade das coisas que plantava pro posseiro5.

\footnotetext{
${ }_{5}^{5}$ Retirado de http://www.museudapessoa.net/pt/conteudo/historia/nao-tenho-vergonha-da-minha-historia-98280
} 
Além disso, a diversidade da sociedade e da cultura brasileira também foram privilegiadas, na medida em que o Museu da Pessoa abriu um espaço para que todas as pessoas pudessem manifestar suas histórias de vida, que também são importantes fontes do nosso patrimônio e da nossa história. Neste aspecto, busca-se também dar voz a determinados grupos sociais e étnicos que durante séculos estiveram excluídos, mas que também são detentores do patrimônio, além de serem elementos essenciais para a compreensão da história e da atualidade brasileira:

contar histórias sempre foi a arte de contá-las de novo, e ela se perde quando as histórias não são mais conservadas. Ela se perde porque ninguém mais fia ou tece enquanto ouve a história. Quanto mais o ouvinte se esquece de si mesmo, mais profundamente se grava nele o que é ouvido. (Benjamin, 1994, p. 198)

É evidente que a dimensão ficcional se faz presente no processo de construção das memórias, que não é composta apenas de fatos reais, mas também de aspectos que abrangem ilusão, fantasia, seleção e esquecimento, e isso está profundamente associado à forma como concebemos as noções de tempo, associando passado, presente e futuro, uma vez que os indivíduos também são guiados por percepções subjetivas e com grande carga emocional. Tal como ocorre nos documentos escritos, no processo de construção de memórias é possível identificar uma multiplicidade de discursos, práticas e representações identitárias, dado que a compreensão dos fatos que vivenciamos está profundamente associado ao nosso lugar social. Para além disso, muitas destas memórias transmitidas oralmente têm grande relevância, pois fazem parte dos costumes e das tradições, entre outras manifestações culturais que são parte do patrimônio imaterial de certas localidades brasileiras, e por isso precisam de ser reconhecidas e conservadas.

Podemos realçar então o Museu da Pessoa como uma forma de não apenas dialogar com a esfera educacional, mas sobretudo de socializar a história de vida das pessoas mediante a perspectiva da Educação Patrimonial .

\section{Educação patrimonial e o Museu da Pessoa}

A sociedade brasileira ao longo da sua história sempre foi marcada por desigualdades sociais e culturais, sendo visível a exclusão de certos grupos étnicos (como os indígenas e os negros) em detrimento de outros (como os imigrantes europeus). Este contexto de desigualdade durante muito tempo se naturalizou em nossa sociedade e principalmente no campo educacional. Entretanto, a partir do desenvolvimento da denominada Educação Patrimonial, tornou-se possível dinamizar as políticas de preservação, recuperando informações acerca do patrimônio social, histórico e cultural do país, atribuindo a determinados agentes sociais sua real importância no processo de construção da identidade nacional: "ao buscar mudanças nesse quadro, alguns museus têm promovido ações que visam estabelecer integração com a comunidade e é, dessa forma, que um dos caminhos privilegiados, nesse sentido, encontrados por tais instituições tem sido a escola" (Azevedo, 2010, p. 311). 
Neste sentido, o governo, em parceria com o Instituto do Patrimônio Histórico e Artístico Nacional (IPHAN), desde a década de 1980, e sobretudo no início do século XXI , passou a investir muitos recursos na chamada "Educação Patrimonial". Este tipo de educação busca promover em diversas regiões do Brasil uma maior aproximação das crianças e adolescentes - integrantes de escolas do Ensino Básico ao Ensino Médio - com grupos étnicos que também são detentores do patrimônio, seja ele material ou imaterial, do país. Além disso, objetiva-se incutir por meio da via educacional a necessidade de se preservar e reconhecer a importância dos testemunhos orais para a melhor compreensão da própria história regional e nacional.

O grande desafio imposto ao contexto de efetivação da Educação Patrimonial reside justamente na dificuldade de se transformar uma mentalidade com a qual a sociedade brasileira convive há mais de quinhentos anos, pautada na exclusão de determinados agentes étnicos em prejuízo de outros, e que se mostra presente em vários espaços do cotidiano brasileiro (seja ele econômico, político, social ou cultural). É extremamente contraditório que mesmo mediante a grandiosidade da pluralidade cultural presente no Brasil, e apesar dos muitos esforços provenientes de vários segmentos sociais, determinados aspectos desta mentalidade ainda colonial encontrem ainda respaldo no interior da sociedade. Contudo, considerando que a mentalidade resulta de um contexto cultural e social específico, que delineia a forma como cada indivíduo percebe e se comporta no mundo, o que a Educação Patrimonial visa estimular é justamente pela via educacional a construção de um contexto propício a lidar de forma positiva com a diversidade. Assim:

a Educação Patrimonial constitui-se de todos os processos educativos formais e não formais que têm como foco o Patrimônio Cultural, apropriado socialmente como recurso para a compreensão sócio-histórica das referências culturais em todas as suas manifestações (...) Considera ainda que os processos educativos devem primar pela construção coletiva e democrática do conhecimento, por meio do diálogo permanente entre os agentes culturais e sociais e pela participação efetiva das comunidades detentoras e produtoras das referências culturais, onde convivem diversas noções de Patrimônio Cultural. (Florêncio, Clerot, Bezerra \& Ramassote, 2014, p. 19)

A exclusão de determinados grupos étnicos como as comunidades negras, indígenas, regionais, entre outras, em detrimento da população branca, vem passando nos últimos anos por um processo constante de reintegração e revalorização. Posto isto, - Museu da Pessoa tem propiciado um acervo riquíssimo que pode ser usado pelos professores que trabalham com a Educação Patrimonial como forma de incentivar um sentimento de pertencimento com relação a estes grupos, resignificando a importância da herança cultural deixada por eles, além de conceber os alunos como também detentores do patrimônio:

valorizar a diversidade cultural e a história de cada pessoa como patrimônio da humanidade é contribuir para a construção de uma cultura de paz. 
Nossa principal missão é a de ser um museu aberto e colaborativo que transforme as histórias de vida de toda e qualquer pessoa em fonte de conhecimento, compreensão e conexão entre pessoas e povos. ${ }^{6}$

Por conseguinte, tanto a Educação Patrimonial, como o Museu da Pessoa, permitem a valorização e a preservação das memórias enquanto elementos fundamentais para a compreensão da história, cultura e sociedade brasileira. Enfim, a preocupação de salvaguardar o patrimônio e todas as suas formas de expressão, existente desde o surgimento do Museu da Pessoa, consolidou-se como uma importante ferramenta, na medida em que ao ultrapassar o limite físico da esfera museológica, permitiu que o público em geral tivesse acesso a estas memórias por intermédio da plataforma digital.

\section{Conclusão}

A sociedade contemporânea encontra-se mediante constantes transformações, sobretudo relativas à evolução das mídias visuais digitais. Assim, da mesma maneira que a sociedade se modifica, as instituições museológicas também tiveram que desenvolver mecanismos de se adequar a essas transformações. As novas tecnologias foram inseridas nos museus, provocando mudanças profundas nos seus discursos e modos de funcionamento. Até metade do século $X X$, os museus eram concebidos conforme modelos tradicionais, em que se limitavam a espaços de exposição de peças cujo público era restrito. No entanto, a partir da emergência da Nova Museologia, os museus passaram a adotar novas formas de atuação, privilegiando assim o caráter sociocultural e a aproximação com as pessoas, que se tornaram parte fundamental dos processos de significação dos mesmos.

O Museu da Pessoa surge como uma expressão viva de uma cultura visual digital em desenvolvimento, em que o acervo é composto por histórias de vida contadas voluntariamente e às quais podemos aceder via ecrã, de forma visual. Por isso, conseguiu se destacar dos demais, na medida em também possibilitou inserir memórias de indivíduos que durante séculos estavam na margem da sociedade brasileira, mostrando assim que as histórias de toda e qualquer pessoa têm valor. Essas memórias auxiliam na preservação da memória oral, na construção e na afirmação da identidade e da memória sociocultural nacional, visto que o desafio contemporâneo dos museus é como abrir espaço para "memórias esquecidas" ou, ainda, como podem transmitir essas memórias para os diferentes tipos de público e a sociedade de maneira geral" (Miziara, 2016, p. 239).

Posto isto, este museu ganhou uma grande relevância no seio da sociedade brasileira, dado que através dele é possível trabalhar sob a perspectiva da Educação Patrimonial, valorizando o discurso oral e salvaguardando a memória e a identidade sociocultural de segmentos populacionais que durante muito tempo estiveram à margem, como as comunidades indígenas e quilombolas, atribuindo-lhes sua real importância enquanto detentoras do patrimônio.

\footnotetext{
${ }^{6}$ Retirado de www.museudapessoa.net
} 
Porém, ainda são necessárias diversas ações para que ocorra a valorização da memória oral, e uma maior aproximação da população, não apenas para com o Museu da Pessoa, mas para com os demais, e para que a questão da virtualidade e da participação sejam experiências frequentes na realidade nacional. Enfim, apesar de já terem ocorridos importantes passos no que tange à Educação Patrimonial, ainda são necessários muitos esforços para que realmente a população se sinta parte da história e da identidade sociocultural brasileira.

\section{AgRAdeCimentos E FinANCiAMENTo}

Gostaríamos de agradecer aos Departamentos de Turismo e de História da Universidade Federal de Juiz de Fora, especialmente o Laboratório de História Econômica e Social e a Pró- Reitoria de Extensão da referida instituição, que através dos projetos: "Mapeamento Arqueológico e Educação Patrimonial na Zona da Mata Mineira " e "As práticas de Educação Patrimonial para o fortalecimento da decratização cultural, do exercício da cidadania e da preservação da memória no Museu Mariano Procópio “, nos forneceram os subsídios e possibilitaram a aquisição de conhecimentos necessários ao desenvolvimento deste artigo. Posto isto, gostaríamos de agradecer também ao Museu da Pessoa, e enaltecer a importância existente no fato deste acervo estar disponível virtualmente, uma vez que potencializa o acesso não apenas a comunidade acadêmica, mas a sociedade como um todo.

\section{REFERÊNCIAS BIBLIOGRÁFICAS}

Alberti, V. (2005). Fontes orais: histórias dentro da história. In C. B. Pinsky(Ed.), Fontes Históricas (pp. 155202). São Paulo: Contexto.

Avelar, L. F. (2015). Museus comunitários no Brasil: o ponto de memória Museu do Taquaril. Dissertação de Mestrado, Centro de Pesquisa e Documentação de História Contemporânea, Programa de PósGraduação História, Política e Bens Culturais, Fundação Getúlio Vargas, Brasil. Retirado de http:// bibliotecadigital.fgv.br/dspace/handle/10438/13691

Azevedo, C. B. de. (2010). Educação patrimonial, ação educativa em museu e ensino-aprendizagem em história. Akrópolis, 18(4), 299-314.

Benjamin, W. (1994). Magia e técnica, arte e política: Ensaios sobre literatura e história da cultura. São Paulo: Brasiliense.

DaMatta, R. (2001). O que faz o Brasil, Brasil? Rio de Janeiro: Editora Rocco Ltda.

Declaração de Quebec (1984). Declaração de Quebec, princípios de base de uma nova museologia. Cadernos de Sociomuseologia, 15(15). Retirado de http://revistas.ulusofona.pt/index.php/ cadernosociomuseologia/article/view/342

Florêncio, S. R. R.; Clerot, P.; Bezerra, J. \& Ramassote, R. (2014). Educação Patrimonial: histórico, conceitos e processos. Brasília-DF: Instituto do Patrimônio Histórico e Artístico Nacional /DAF/COGEDIP/CEDUC. Retirado de http://portal.iphan.gov.br/uploads/publicacao/EduPat_EducacaoPatrimonial_m.pdf

Gonçalves, J. R. S. (2007). Antropologia dos objetos: coleções, museus e patrimônios. Rio de Janeiro: IPHAN. 
Gonçalves, J. R. S. (1996). A retórica da perda: os discursos do patrimônio cultural no Brasil. Rio de Janeiro: Editora da UFRJ/IPHAN.

Hampaté Bâ, A. (2010). Tradição viva. In J. Ki-Zerbo (Ed.), História Geral da África: Metodologia e Pré-história da África (n $\left.{ }^{\circ}, \mathrm{pp} .167-212\right)$. Brasília: UNESCO.

Hartog, F. (2014). Regimes de historicidade: presentismo e experiências do tempo. Belo Horizonte: Autêntica.

Henriques, R. M. N. (2004). Memória, museu e virtualidade: um estudo sobre o museu da Pessoa. Dissertação de mestrado, Universidade Lusófona da Humanidades e Tecnologias, Lisboa, Portugal. Retirado de http://www.museologia-portugal.net/files/upload/mestrados/rosali_henriques_1.pdf

Huyssen, A. (1996). Escapando da amnésia: o museu como cultura de massa. In Memórias do modernismo. Rio de Janeiro: Editora da UFRJ.

Huyssen, A. (2000). Seduzidos pela memória. Rio de Janeiro: Aeroplano.

Ibram. Portal do Instituto Brasileiro de Museus. Retirado de http://www.museus.gov.br/

Ki-Zerbo, J. (1979). Um continente descobre o seu passado. O Correio da UNESCO, 32.

Ki-Zerbo, J. (Ed.) (2010). História geral da África, I: Metodologia e pré-história da África. Brasília: Unesco. Retirado de http://unesdoc.unesco.org/images/0019/001902/190249POR.pdf

Le Goff, J. (2003). História e memória. Campinas: SP: Editora FGV.

Lévy, P.(1999). Cibercultura. São Paulo: Ed. 34 Ltda.

Lévy, P. (1996).O que é o virtual. São Paulo: Ed. 34 Ltda.

Miziara, R. (2016). Experienciar museus: um olhar sobre o Museu da Pessoa. Revista do Centro de Pesquisa e Formação, 2, 236-248. Retirado de http://www.sescsp.org.br/files/artigo/fgafe4f5-a04c-4dab-geb8boeere12dccb.pdf

Moutinho, M. (1989). Museus e sociedade. Reflexão sobre a função social do museu. Cadernos de Patrimônio, 5 .

Muchacho, R.(2005). Museus virtuais: a importância da usabilidade na mediação entre o público e o objeto museológico. In Livro de Actas do $4^{\circ}$ Congresso SOPCOM (pp. 1540-1547). Retirado de http://revistas. ua.pt/index.php/sopcom/article/view/3293/3055

Museu da Pessoa. Retirado de http://www.museudapessoa.net/pt/home

Nascimento, R. (2014). Não tenho vergonha da minha história. Retirado de http://www.museudapessoa.net/ $\mathrm{pt} /$ conteudo/historia/nao-tenho-vergonha-da-minha-historia-98280>

Nora, P. (1993). Entre memória e história: a problemática dos lugares. Revista do Programa de Estudos PósGraduados em História, 10, 7-28.

Primo, J. S. (1999). Pensar contemporaneamente a museologia. Cadernos de Sociomuseologia, 16, 5-38.

Santos, M. P. (2014). Quando vou rezar, peço licença à natureza. Retirado de http://www.museudapessoa. net/pt/conteudo/historia/quando-vou-rezar-peco-licenca-a-natureza-96217

Simões, A.; Bezerra, T. \& Henriques, P. (2004). A importância das ontologias num Museu Virtual. Comunicação apresentada no II Congresso Internacional de Investigação e Desenvolvimento SócioCultural, Paredes de Coura. 
Silva, S.M.M. (2009). A “musealização" do presente: mídia, memória e esquecimento, questões para pensar a história hoje. Tempo e Argumento, 1, 123-125.

Soares, B.C.B. \& Scheiner, T.C.M. (2009). A ascensão dos museus comunitários e os patrimônios "comuns": um ensaio sobre a casa. In Anais do X ENANCIB (pp. 2469-2489). Retirado de http://enancib.ibict.br/ index.php/enancib/xenancib/paper/viewFile/3311/2437

Worcman, K. (2011). Museu da Pessoa: o que fazer com as dúvidas? Oralidades, 5(10), 75-88.

\section{NOTAS BIOGRÁFICAS}

Anna Clara Marotti Magalhães. Universidade Federal de Juiz de Fora - Departamento de Turismo. É Bacharela em Ciências Humanas pela Universidade Federal de Juiz de Fora (2013) e Bacharela em Turismo pela Universidade Federal de Juiz de Fora (2016).

E-mail: acmm1990@gmail.com

Rua Coronel Goulart, n 129, Boa Vista/ CEP: 37505-022, Itajubá, Minas Gerais, Brasil

Letícia Maia Dias. Universidade Federal de Juiz de Fora - Departamento de História.

É Licenciada em História e Habilitada em Patrimônio pela Universidade Federal de Juiz de Fora (2016).

E-mail: leticiamaiadias@hotmail.com

Rua Doutor Acácio Teixeira, no 77, apartamento: 101, Grajaú / CEP: 36052360, Juiz de Fora, Minas Gerais, Brasil

* Submetido: 24/02/2017

* Aceite: 22/04/2017 